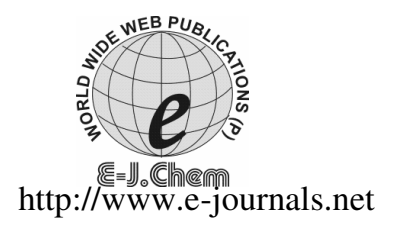

ISSN: 0973-4945; CODEN ECJHAO

E-Journal of Chemistry

2010, 7(4), 1304-1307

\title{
Assessment of Soil Fertility of Grape Field at Bijapur District, Karnataka, India
}

\author{
A.S.PUJAR* ${ }^{*}$ M.S.YADAWE, U.S.PUJERI, \\ K.G.PUJARI and S.C.HIREMATH \\ S.B.Arts and K.C.P. Science College, \\ Bijapur -586103, Karnataka, India. \\ shiva4565@rediff.com
}

Received 15 January 2010; Accepted 10 March 2010

\begin{abstract}
Assessment of soil fertility at Bijapur district (Karnataka, India), grape yard of various localities was undertaken. Grape is an important fruit crop of northern parts of Karnataka and it is grown over 9000 hectors. The survey includes 15 grape yards and surface soil samples up to depth of 30 $\mathrm{cm}$ were collected and after drying were passed through $2 \mathrm{~mm}$ sieve. The soil samples were analyzed for various attributes. The data on analysis revealed that the soil was clay in texture which is considered quite fit for grape growing. The soil $\mathrm{pH}$ of various grape fields ranged from 7.2 to 8.8 slightly above the optimum range. The electrical conductivity values varied from 0.18 to $1.75 \mathrm{dS} / \mathrm{m}$ well below the critical concentration. The carbon content ranges from 0.23 to $1.01 \mathrm{~kg} / \mathrm{ha}$. The available nitrogen was in lower range 45 to $337.5 \mathrm{~kg} /$ hector. This might be due to high range of mineralization due to high temperature (dry zone) and loss of nitrogen in the form of ammonia. The soil available phosphorous content range from 15.00 to $48.9 \mathrm{~kg} / \mathrm{hector}$ which was medium in range. The available potassium ranged from 115 to $592 \mathrm{~kg} /$ hector which were high range in all the grape fields.
\end{abstract}

Keywords: Soil fertility, Grape, Bijapur district.

\section{Introduction}

Soil fertility, compatibility and erodability are the elements of soil quality. Among these, the problem of decline in soil fertility endangers the maximum growth in productivity ${ }^{1}$. Warren and Agnew $^{2}$ described that, of the threats to sustainability, the threat due to soil fertility depletion is the most serious. Depending upon the cropping pattern, leaching, erosion etc, soil loses a considerable amount of nutrients every year. If the cropping pattern is continued 
over a period of time without nutrients being restored to the soil, its fertility will be reduced and crop yields will decline. Poor soil fertility conceives sparse plant cover, which promote erosion vulnerability. This happens because $90 \%$ of plant available N, 50-60\% K, $25-$ $30 \% \mathrm{P}$ and almost $70 \%$ micronutrients residue in organic matter ${ }^{3}$.

Soil testing provides information regarding nutrient availability in soils which forms the basis for the fertilizer recommendations for maximizing crop yields. Soil fertility maps are meant for highlighting the nutrient needs, based on fertility status of soils (and adverse soil conditions which need improvement to realize good crop yields. Obviously, a soil fertility map for a particular area can prove highly beneficial in guiding the farmers, manufacturers and planners (associated with fertilizer marketing and distribution) in ascertaining the requirement of various fertilizers in a season/ year and making projections for increased requirement based on cropping pattern and intensity.

Soil formation is a constructive as well as destructive process. Destructive process predominates the physical and chemical breaking down of materials, plants and animal structures, which results in the partial loss of more soluble and volatile products. Constructive forces develop new chemical compounds, both mineral and organic matter. It provides new distribution or association characteristics, structural properties as well as chemical compositions. These factors influence the plant growth in the soil ${ }^{4}$. The Bijapur district is one of the important districts of Karnataka because of horticultural crops. The main horticulture crops cultivated in the district are grapes, pomegranates, lime etc. The yield of crop depends on soil fertility and presence of micronutrients in the soil. The soil condition is of great importance, because it is universal medium for plant growth, which supplies essential nutrients to the plants.

\section{Experimental}

Sixteen representative sites in and around Bijapur district were selected for the characterization of the soil samples. From the selected sites, samples were collected in polythene bags, as per the standard procedures recommended by United States Department of Agricultural Science ${ }^{5}$. Quartering technique was used for preparation of soil samples. The soil samples were dried in air and passed through $\sim 2 \mathrm{~mm}$ sieve, stored in polythene bags.

Physicochemical parameters were determined by the methods suggested in the literature by Richards ${ }^{5}$ and Trivedi and $\mathrm{Geol}^{6}$. The $\mathrm{pH}$, electrical conductivity, organic carbon (Walky and Black) ${ }^{7}$, available phosphorus (Olsen et al) ${ }^{8}$ and available potassium (Jackson) ${ }^{9}$ were determined.

\section{Results and Discussion}

The physicochemical characteristics are given in Table 1, revealed that, soil was clay in texture which is considered to be quite fit for grape growing. The $\mathrm{pH}$ values of the soil samples ranged from 7.2 to 8.8 , slightly above the optimum range considered to be satisfactory for grape cultivation. The increased electrical conductivity (EC) values were observed in the range of 0.18 to $1.75 \mathrm{dS} / \mathrm{m}$. The increase in EC value may be due to agricultural run off and accumulation of salts ${ }^{10}$. Organic matter content varied from 0.23 to $1.01 \mathrm{~kg} / \mathrm{ha}$. The higher organic matter contents (S11) may be due to decay of plants recedes in soil ${ }^{11}$. Available nitrogen content in the grape fields ranged from 45 to $337.5 \mathrm{~kg} / \mathrm{ha}$. Lower nitrogen values recorded for sample S12 and higher value was recorded for S16. The higher available nitrogen content in the grape soil is due to application of fertilizers. 
Table 1. Physicochemical parameters of soil of Bijapur District.

\begin{tabular}{cccccccc}
\hline $\begin{array}{c}\text { Sample } \\
\text { No. }\end{array}$ & Taluka & $\mathrm{pH}$ & $\begin{array}{c}\text { Electrical } \\
\text { conductivity in, } \\
\mathrm{dS} / \mathrm{m}\end{array}$ & $\begin{array}{c}\mathrm{C} \\
\mathrm{kg} / \mathrm{ha}\end{array}$ & $\begin{array}{c}\mathrm{N} \\
\mathrm{kg} / \mathrm{ha}\end{array}$ & $\begin{array}{c}\mathrm{P} \\
\mathrm{kg} / \mathrm{ha}\end{array}$ & $\begin{array}{c}\mathrm{K} \\
\mathrm{kg} / \mathrm{ha}\end{array}$ \\
\hline S1 & & 7.71 & 1.75 & 0.64 & 292.5 & 21.4 & 398.6 \\
S2 & Bijapur & 7.33 & 0.97 & 0.37 & 405.0 & 28.6 & 139.4 \\
S3 & & 8.30 & 0.35 & 0.30 & 320.0 & 15.0 & 120.0 \\
\hline S4 & & 7.34 & 0.65 & 0.29 & 48.0 & 26.3 & 192.9 \\
S5 & B.Bagewadi & 7.85 & 1.08 & 0.56 & 360.0 & 27.3 & 394.1 \\
S6 & & 7.50 & 1.20 & 0.60 & 285.0 & 29.1 & 152.0 \\
\hline S7 & & 8.60 & 0.33 & 0.73 & 55.0 & 32.0 & 120.0 \\
S8 & Muddebihal & 8.30 & 0.19 & 0.46 & 180.0 & 23.0 & 122.0 \\
S9 & & 8.10 & 0.48 & 0.43 & 170.0 & 25.0 & 130.0 \\
\hline S10 & & 8.40 & 0.90 & 0.56 & 80.0 & 20.0 & 125.0 \\
S11 & Indi & 8.60 & 0.19 & 0.72 & 140.0 & 40.0 & 115.0 \\
S12 & & 8.50 & 0.16 & 1.01 & 45.0 & 38.0 & 118.0 \\
\hline S13 & & 8.80 & 0.18 & 0.97 & 160.0 & 26.0 & 120.0 \\
S14 & Sindagi & 7.78 & 0.80 & 0.93 & 292.5 & 19.4 & 592.0 \\
S15 & & 7.62 & 0.38 & 0.72 & 290.0 & 20.4 & 409.4 \\
S16 & & 7.25 & 0.77 & 0.23 & 337.5 & 48.9 & 359.1 \\
\hline
\end{tabular}

The available phosphorus in the soils ranged from 15 to $48 \mathrm{~kg} / \mathrm{ha}$. The lower and higher values of phosphorus were reported for samples S3 and S16 respectively. Since the soils are rich in hydrated as well as amorphous oxides of $\mathrm{Fe}$ and $\mathrm{Al}$, the potent source of "P" immobilization, $\mathrm{P}$ content in the sample S3 (Badrinath et al; 1986) ${ }^{12}$. Available P content was medium at some sites in the study area where $\mathrm{pH}$ was neutral. The near neutral $\mathrm{pH}$ have a significant role in enhancing $\mathrm{P}$ availability. The available $\mathrm{P}$ content, increases with $\mathrm{pH}$ value and decreases with organic carbon. The increase in available phosphorus due to increase in $\mathrm{pH}$ value may be due to lowering of activities of $\mathrm{Fe}^{3+}$ and $\mathrm{Al}^{3+}$ which increases the solubility of strangle and variscite and increases electro negativity of colloidal complex with a consequent decreases in sorption of phosphorus. At some places phosphorus was high, which may be due to different nutrient management practices among the farmers ${ }^{13}$.

Data pertaining to available potassium ranged from 115 to $592 \mathrm{~kg} / \mathrm{ha}$. The sample S11 has low potassium content due to lower $\mathrm{pH}$ value ${ }^{14}$. The available potassium content was high in sample S14. In highly weathered soils, strong weathering had reduced potassium content.

\section{Conclusion}

The present study revealed that there is wide variation in soil fertility status of Bijapur district. The different nutrients have to be restored through chemical fertilizers or organic manures to maintain soil health. Based on soil fertility and climatic conditions Bijapur district is well suited for Horticulture crops.

\section{Acknowledgment}

Authors are thankful to the Principal, Head of the Department of Chemistry and Administrators, S. B.Arts and K.C. P. Science College, Bijapur providing Laboratory facilities and UGC New Delhi for financial assistance. 


\section{References}

1. $\quad$ Katyal J C, J Indian Soc Soil Sci., 2003, 51, 378-387.

2. Warren A and Agnew C, An assessment of desertification and Land degradation. Arid and Semi arid areas. International Institute of Environmental Department, Drylands Farming Ecology and Conservation Unit, University College London, U.K, 1988.

3. Stevenson F S, Organic Matter and Nutrient availability. In; Non-Symbiotic Nitrogen fixation and Organic Matter in the Tropics. Trans. $12^{\text {th }}$ Int Cong Soil Sci., New Delhi, India, 1982, 137-51.

4. Samuel T L and Werner L N, Soil fertility and Fertilizers Macmillan Publications Co., $3^{\text {rd }}$ Edition, 1975.

5. Richards L A, Diagnosis and Improvement of Saline and Alkaline Soil, United States Salinity Laboratory staff, US Department of Agriculture Hand Book, 1986, 60, 171.

6. Trivedi R K and Geol P K, Chemical and Biological Methods for Water Pollution Studies, Environmental Publications, Karad, 1984, 64-65.

7. Walkey A and Black A I, Soil Sci., 1934, 37, 28-35.

8. Olsen S R, Cole C V, Watanbe F S and Dean I A, USDACirc. 1954, 939, 1-19.

9. Jackson M L, Soil Chemical Analysis, Prentice Hall India Pvt Ltd New Delhi, 1967 p. 498.

10. Shrivastava V S, Rai A K and Mehortra R C, Indian J Environ Health, 1989, 31, 314-320.

11. Deshmukh A.M and Godbole S.H, Recent Research Ecol Environ and Pollution, 1998, 1, 61-73.

12. Badrinath, Krishnappa A N, Patil B N, Kenchaiah K and Balakrishnarao K, J Indian Soc Soil Sci.,1986, 34, 436-438.

13. Dhanya V, Mathews P L, Patil and Dosag G S, Karnataka J Agric Sci., 2009, 22(1) 77-80.

14. Ranganathan A and Satyanarayana T, J Indian Soc Soil, Sci., 1980, 28, 148-153. 


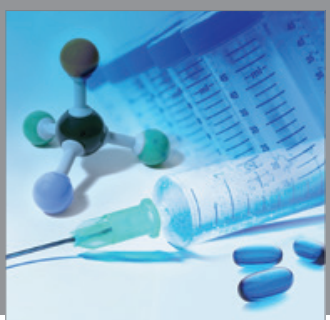

International Journal of

Medicinal Chemistry

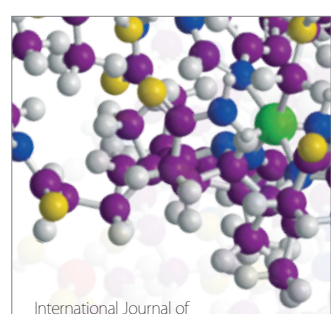

Carbohydrate Chemistry

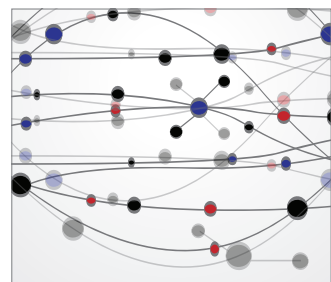

The Scientific World Journal
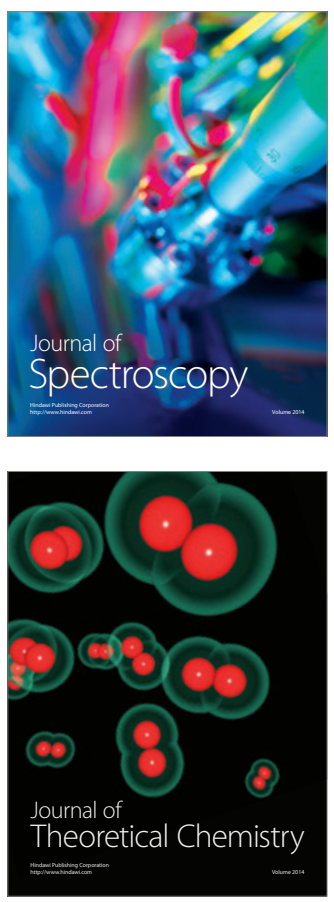
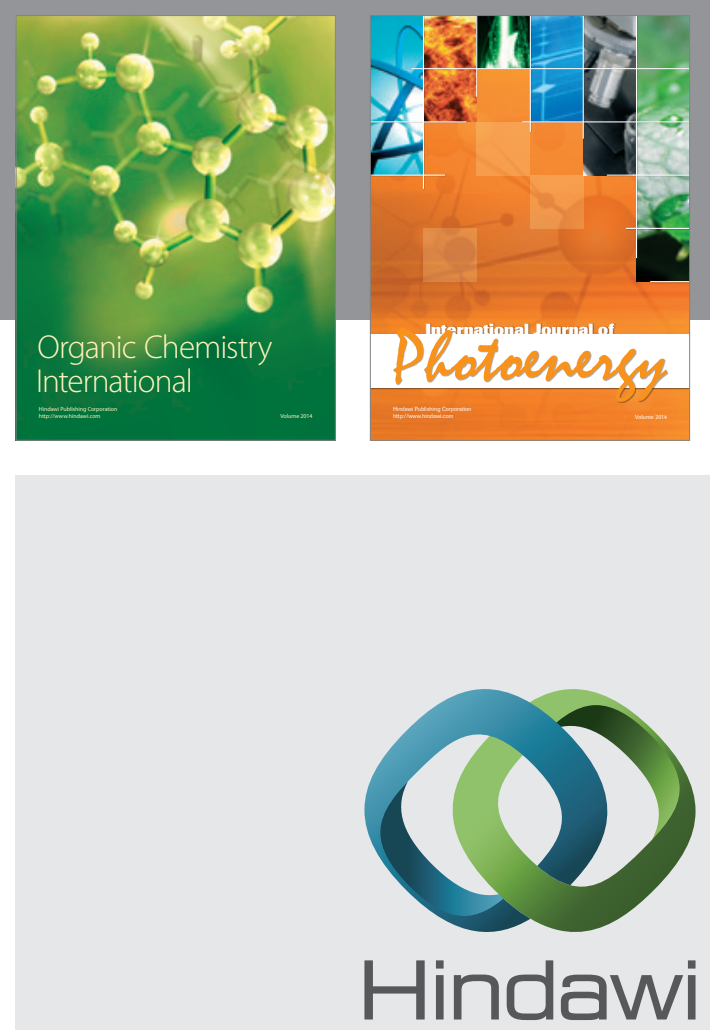

Submit your manuscripts at

http://www.hindawi.com
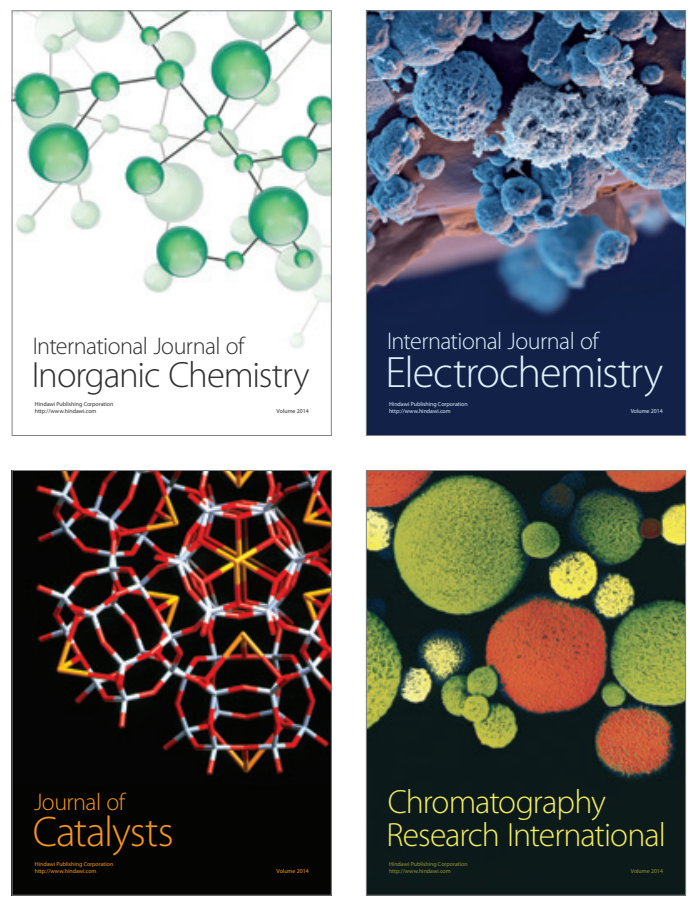
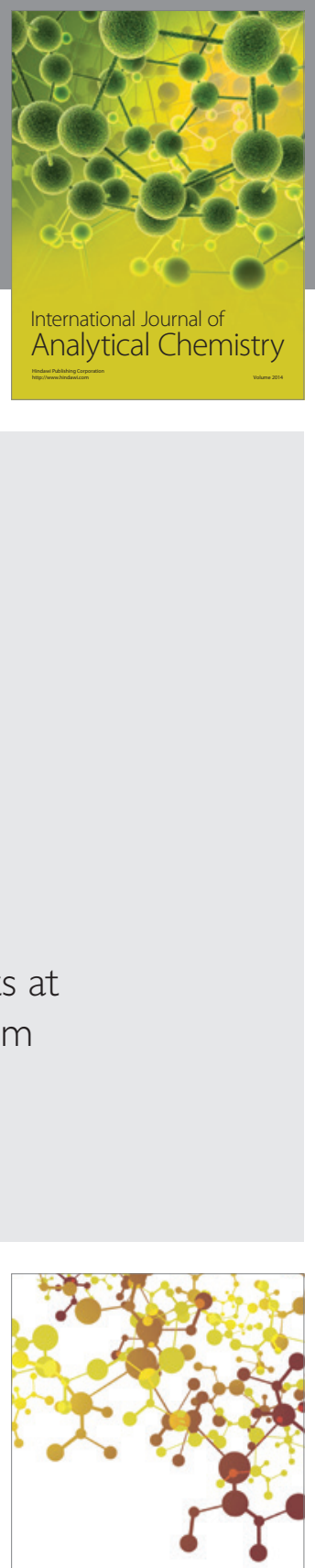

Journal of

Applied Chemistry
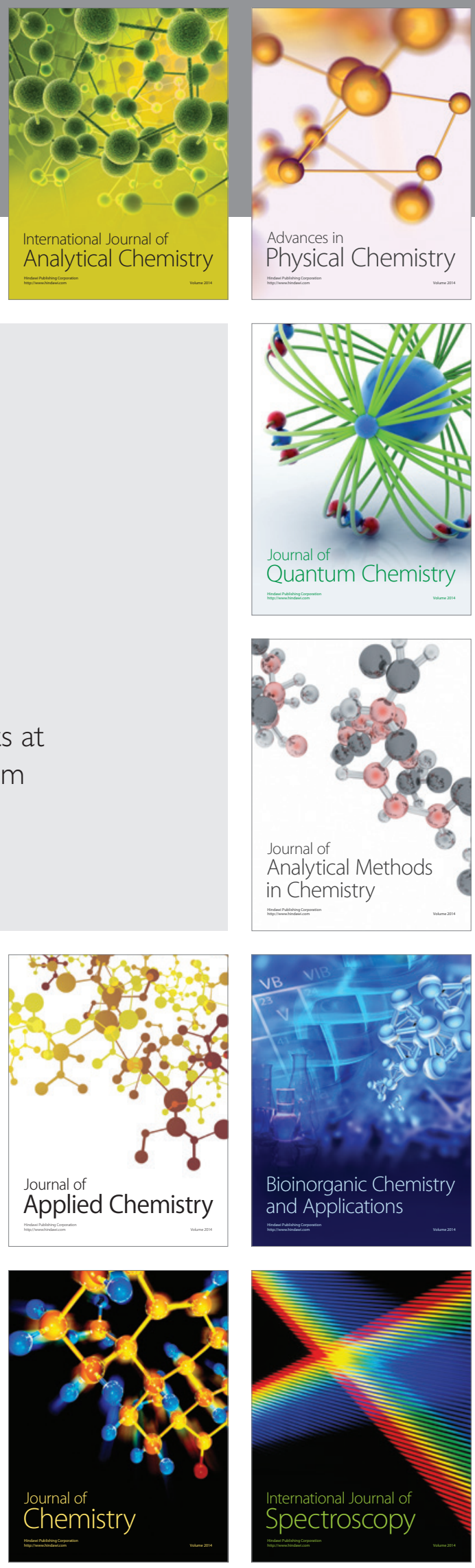